\title{
Analysis on Investment Correlation between Hong Kong Economy and Mainland Economy
}

\author{
To Pokwai ${ }^{1, a}$ \\ ${ }^{1}$ School of Astronautics,Beihang University,Beijing 100191,China \\ a854800331@qq.com
}

\begin{abstract}
Keywords: Economy investment, investment correlation, model, index
\end{abstract}
\begin{abstract}
Investment theory of economic integration includes analysis on static effect and dynamic effect, this paper uses analysis methods of combing with theory and practice as well as relates development state of mainland in China and Hong Kong to analyze investment correlation of economy integration in mainland and Hong Kong. It starts from three aspects of trade relation, investment relation and communication relation of personnel to establish correlation index, it uses demonstration model to make test on investment effect and puts forward the referential measures for investment in mainland and Hong Kong.
\end{abstract}

\section{Introduction}

Since the opening-up and reforming of China in 1997, the manufacturing industry of Hong Kong successively moves to mainland, so that it realizes transformation and promotion $[1,2,3]$ from industrial structure to service industry. In these decades, the economy and trade cooperation between Hong Kong and mainland are quickly developing relying on the highly complementary factor endowment and gradient of economy and technology as well as close relation in geology, affinity and cultural origin. The economic integration organization in mainland and Hong Kong take important promotion effect [4,5] on economic development, especially for investment increase of mainland and Hong Kong. The economic cooperation of them has become the new sport of economic development in the beginning of 21st century. Chinese Central Government and Hong Kong Special Administrative Region Government has signed Arrangement on Establishing Closer Economy and Trade Relations between Mainland and Hong Kong, which enables the economy and trade exchange to become increasingly close, meanwhile two-way investment circulation becomes increasingly active. Mainland has become to be the important target for investment by Hong Kong. Meanwhile it also gradually becomes the important source place of some investment by Hong Kong. With the actual implementation of provisions in investment field, the economy and trade exchange of mainland and Hong Kong will become closer and mutual investment will get further development. At the same time, the gradually increase in supplementary agreement also fully indicates determination and standpoint for mainland and Hong Kong to promote investment liberalization. This paper starts from three aspects of trade relation, investment relation and communication relation of personnel to establish correlation index. This paper calculates their economy dependence and total correlation index of Hong Kong and mainland; it also uses two indexes to respectively analyze economy correlation of Hong Kong and mainland.

\section{Selection and measurement of economy correlation index of Hong Kong and mainland}

Index selection:This paper adopts method of index integration measurement and selects correlation index from the perspective of angle investment, trade, personnel communication that closely relate to trade and economy of Hong Kong and Mainland. There are many methods of establishing correlation index in the perspective of pure theory and method, but it should consider the due characteristics of index in reality, firstly, it can use annual public data to make calculation, secondly it should be sensitive to changes in annual economy of Hong Kong and mainland, thirdly, it can reflect the existing problems in reality. 
On establishing economy correlation index of Hong Kong and mainland, it should start from 2 perspectives to confirm index from. Firstly, economy dependence of Hong Kong and mainland, it is composed of dependence of mainland to Hong Kong and dependence of Hong Kong to mainland. Secondly, the total economy correlation index of Hong Kong and mainland, it should start from 3 perspectives of trade correlation of Hong Kong and mainland, investment correlation of Hong Kong and mainland, personnel communication correlation of Hong Kong and mainland to establish total index.

Measurement of economy correlation:With the increasingly close relations of Hong Kong and mainland in trade as well as quick enhancement on trade dependence of Hong Kong to mainland, mainland has played an the most important role in foreign trade relations of Hong Kong. It selects dependence of total trade amount between Hong Kong and mainland as one of the indexes for economy of Hong Kong and mainland, the dependence formula of Hong Kong and mainland is as follows:

$$
\begin{aligned}
& \text { A dependence on exports to } \mathrm{B}=\quad \text { A to } \mathrm{B} \text { import dependence }= \\
& \frac{\text { A exports amounted to } \mathrm{B}}{\text { A export value }} \times 100 \% \quad \text { (1) } \frac{\text { A while imports amounted to } \mathrm{B}}{\text { A amount of imports }} \times 100 \% \\
& \text { A trade dependence on B's }=\frac{\text { A export amounts to B }}{\text { A Import and Export Amount }} \times 100 \%
\end{aligned}
$$

In order to well reflect investment dependence of mainland and Hong Kong, it selects investment percentage in overall foreign investment amount on Hong Kong to mainland as the dependence on mainland to Hong Kong. It selects the standard Chinese citizens residing abroad and their investment proportion of foreigners in Hong Kong as investment dependence of Hong Kong to mainland. The dependence formula of Hong Kong and mainland is as follows: Investment dependence on the mainland to Hong Kong =

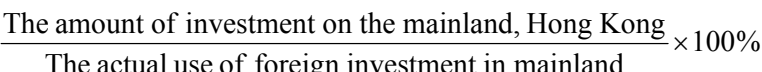
Import dependence on the mainland, Hong Kong =

$$
\frac{\text { The amount of investment in the mainland for Hong Kong }}{\text { The overall amount of investment in mainland }} \times 100 \%
$$

The technology and science exchange of mainland and Hong Kong is in continual development and with the exchanges in each field; the exchange content is very universal, including visit and interview, cooperation and science research, technology training, business discussion, scholar conference etc. It selects availability of statistics data of Hong Kong and mainland as well as politics and restriction of opening degree of Hong Kong and mainland, which makes plenty of data can not be obtained, so it uses the percentage of tourists of Hong Kong travelling to mainland in the number of mainland immigration as the personnel

Mainland to Hong Kong exchanges and personnel exchanges dependence

$$
\begin{aligned}
& =\frac{\text { Number of Hong Kong to mainland }}{\text { Mainland tourist arrivals }} \times 100 \% \\
& \text { Hong Kong's dependence on the mainland between staff } \\
& =\frac{\text { Number of mainland China from Hong Kong to }}{\text { The total number of tourists to Hong Kong }} \times 100 \%
\end{aligned}
$$

Calculation of the overall correlation index is as follows: respectively calculate the average value of three indexes of correlation index of Hong Kong and mainland trade, investment correlation index of Hong Kong and mainland, personnel exchange correlation index of Hong Kong and mainland, plus these three average values and then get the average sum, use each index value to divide sum of average value to get contribution rate of average value, then use annual index of these three indexes to multiply contribution rate of average value and then add to each other to get the overall correlation index. The overall correlation index of Hong Kong and mainland is indicated in table 1: 
Table 1 Overall correlation index of Hong Kong and mainland Unit: \%

\begin{tabular}{|l|l|l|l|l|}
\hline Year & $\begin{array}{l}\text { Trade correlation } \\
\text { index of Hong Kong } \\
\text { and mainland }\end{array}$ & $\begin{array}{l}\text { Investment correlation } \\
\text { index of Hong Kong } \\
\text { and mainland }\end{array}$ & $\begin{array}{l}\text { Personnel exchange } \\
\text { correlation index of Hong } \\
\text { Kong and mainland }\end{array}$ & $\begin{array}{l}\text { The overall } \\
\text { correlation } \\
\text { index }\end{array}$ \\
\hline 2005 & 8.70 & 6.88 & 3.65 & 7.08 \\
\hline 2006 & 8.30 & 3.56 & 3.44 & 5.66 \\
\hline 2007 & 8.65 & 2.43 & 3.58 & 5.43 \\
\hline 2008 & 8.44 & 3.97 & 3.75 & 5.93 \\
\hline 2009 & 8.47 & 5.17 & 3.89 & 6.40 \\
\hline 2011 & 9.09 & 11.61 & 3.78 & 8.99 \\
\hline 2012 & 8.73 & 12.92 & 3.05 & 9.17 \\
\hline 2013 & 8.73 & 10.22 & 3.41 & 9.26 \\
\hline
\end{tabular}

The overall correlation index of Hong Kong and mainland is in the increase trend, it increases from $7.08 \%$ in 2005 to $9.26 \%$ in 2013 . Political factors always plays determinative effect on economy of Hong Kong and mainland, economic relations also have obvious improvement. Close economy correlation means non-separation in politics, with the opening-up of personnel of Hong Kong and mainland, the correlation of them is will gradually increase.

\section{Factor analysis on affecting correlation relations of Hong Kong and mainland}

Analysis on influential factor:The economic growth of mainland Hong Kong is actually the process of gradually absorption and integration under the structure of economy integration by using their geological advantages to enable economy achieve certain scale and form specialized labor division, reduce cost and increase economic profit. After one transnational enterprises achieving scale economy, it will form stronger radiation, acceleration and demonstration effect to promote investment of other transnational enterprises, and fully use comparative advantages to produce scale economy. This will enable the production, management; distribution of economic entities to have higher efficiency and strengthen their economic strength, the interaction relation of them will further strengthen. On the investment of all-around exploration and application of mainland investment to Hong Kong, especially to actively absorb the direct investment of large-scale transnational enterprises in mainland, relay on the integration trend of mainland to accelerate the key enterprises of mainland to be integrated into large-scale transnational enterprises and become the production section. Meanwhile, it should further explore and use the opening field of Hong Kong to establish and perfect two-way investment situation.

Economic integration reduces the restrictions of goods and factor circulation in mainland and Hong Kong, as well as increases the overall competition in international market, so that it has positive effect on investment effect of economic integration. Economic integration has promoted increase in investment flow to certain extent. If they restrict the quantity of international direct investment flowing into mainland and Hong Kong, the establishment of CEPA will enable each market combination to form common large market due to economic integration structure, and promote foreign investors to set up new branch organization for investment and make reasonable adjustment as well as make scaled investment centralized in the area with regional advantage, so it causes increase in investment inflow.

Under CEPA structure, parties strengthen integration in fields such as investment promotion, industry cooperation etc and promotes facilitation in trade and investment by highly transparent and high standard exchange and cooperation, and meanwhile it accelerates competition. Hong Kong investment flows into mainland and mainly focuses on medium-sized and small enterprises, in the service industry coming into mainland, there are 17 industries reduce the threshold and other places all loosen restrictions to attract middle and small capital come into mainland. It accelerates competition in management and consultation industry, bank security industry, advertisement and insurance industry etc. Hong Kong investment inflow is accelerating and mainly flows into Pearl 
River Delta, Yangtze River delta, Beijing Tianjin Hebei Economic Zone of Bohai, Hangzhou, Suzhou, Nanjing representative teams etc all come to Hong Kong and sign a series of agreement on trade, investment, cooperation of medium-sized and small enterprises to actively introduce into Hong Kong investment.

Demonstration analysis:From the overall to make analysis on factors affecting economic correlation of Hong Kong and mainland, relation of gross domestic product is one of the factors affecting the overall correlation of economy, foreign exchange reserve of Hong Kong and mainland is also one of the factors. So it uses GDP and foreign exchange reserve as explanatory variable to measure the overall correlation index of Hong Kong and mainland.

The time order of economic correlation of Hong Kong and mainland is indicated in figure 1, in order to analyze the influential factors on economic correlation index of Hong Kong and mainland, it uses HPY which parameter is 100 as explanatory variable after filtration to make fitting, the first explanatory variable is GDP ratio of Hong Kong and mainland, X1: price GDP ( ten million dollars) that year in China/ current price of Hong Kong GDP( ten million dollars), the second explanatory variable is the foreign exchange reserve ratio, X2: foreign exchange reserve of China (ten million dollars)/ foreign exchange reserve of Hong Kong (ten million Hong Kong dollars), uses HP which parameter is 100 after filtration as explanatory variable, and adds the delayed item of explained variable to establish model, the sample range is the data from 1996 to 2013. The estimated result of model is as follows:

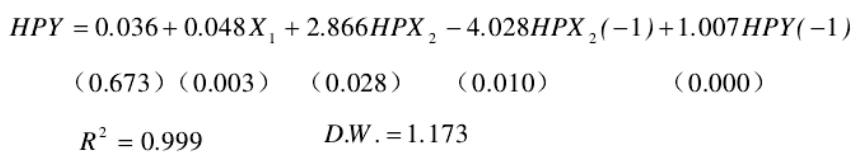

The model result indicates that except for constant term, estimated value of each parameter is not 0 under the distinct level of 5\% (in the bracket is $\mathrm{P}$ value). Whether the test model has spurious regression, it makes ADF test on residual of spurious regression, and the test result is indicated in the following table 2, refuses the original assumption under the distinct level of $5 \%$ and accepts the conclusion without unit root, the residual is table, so there is no situation of spurious regression.

Use the correlation trend value HP of Hong Kong and mainland after filtration as the explained variable, HPY parameter is 100, the first influential factor is trade correlation index (indicated by $\mathrm{X} 1$ ) of Hong Kong and mainland, the exchange rate of RMB to exchange Hong Kong dollar is the second influential factor (indicated by X2), the delayed item of explained variable is also one of the part of model. The regression result of model is as follows:

$$
\begin{aligned}
H P Y= & -2.198+0.210 X_{1}+0.179 H P X_{2}+1.042 H P Y(-1) \\
& (0.001) \quad(0.000) \quad(0.018)
\end{aligned}
$$

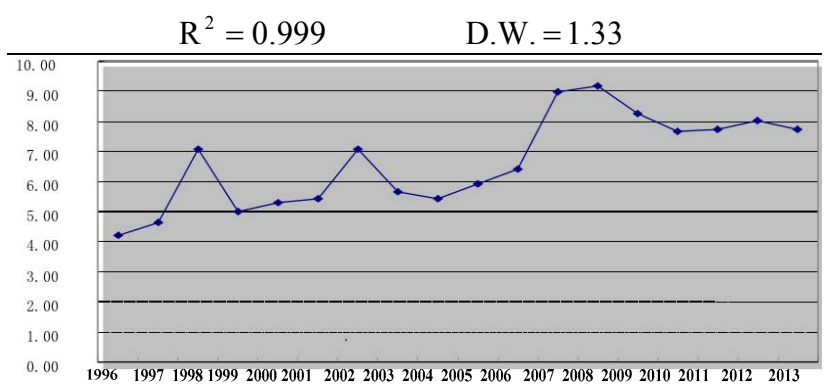

Figure 1 Overall economy correlation

Model result indicates that the estimated value of each parameter is not 0 under the distinct level of 5\% (in the bracket is $\mathrm{P}$ value) and test the residual of model, the test result is indicated by the following table:

Table 2 Test of unit root 


\begin{tabular}{cccc} 
& t-Statistic & Prob. \\
\hline Augmented Dickey-Fuller test statistic & -2.676005 & 0.0996 \\
\hline Test critical values: & $1 \%$ level & -3.920350 & \\
& $5 \%$ level & -3.065585 & \\
& $10 \%$ level & -2.673459 & \\
\hline
\end{tabular}

Refuse the original assumption under the distinct level and accept conclusion of unit root, the residual is stable, so there is no situation of spurious regression. Because there is delayed item of explained variable appears in the model, we make LM test for model, LM test result $\quad(p=1)$ is as follows: as a result, $\mathrm{P}$ value is not too small, so residual has no order correlation.

Table 3 Breusch-Godfrey Serial Correlation LM Test

\begin{tabular}{cccc}
\hline F-statistic & 3.208272 & Prob. F(1,12) & 0.0985 \\
Obs ${ }^{*}$ R-squared & 3.586247 & Prob. Chi-Square(1) & 0.0583 \\
\hline
\end{tabular}

From the model we can see that trade correlation index of Hong Kong and mainland has obvious acceleration effect on investment correlation index of Hong Kong and mainland, when trade correlation index increases by $1 \%$, investment correlation index will increase by $0.21 \%$. Meanwhile, when the exchange rate of RMB to Hong Kong dollars increases by one unit, the index of investment correlation will increase by $0.179 \%$. In the investment correlation of Hong Kong and mainland, investment of Taiwan merchant in mainland has larger proportion than that of mainland in Hong Kong, with value increase in RMB, there are more and more exchanged Hong Kong dollars, then there are more and more Taiwan merchant want to make investment in mainland, so RMB value increases, so investment correlation of Hong Kong and mainland will be closer.

\section{Conclusion}

It has made outstanding contributions on economic structure adjustment in domestic and resources optimization as well as prosperity and common development of Hong Kong and mainland, meanwhile, mainland as the resources for economic development of Hong Kong, it provides broad economy space for industrial structure updating of service industry and manufacturing industry, promotes economic transformation and development in Hong Kong, enables Hong Kong to be one modern international city integrates service and finance etc. In recent years, the investment and trade cooperation of Hong Kong and mainland achieve certain depth and breadth. CEPA enables economic combination of Hong Kong and mainland as well as development of economic integration to the peak. The economic combination in aspects of good trade, service trade, investment trade facilitation etc produce has big and profound effect on economic combination. In the development of economic integration, Central Government and Hong Kong Special Administrative Region Government together discuss and cooperate by concerted effort; it will inevitably realize the mutual benefit to the maximum extent as well as sustainable prosperity and win-win in economy.

\section{References}

[1] Dong Yan. Strategy on Deep Integration, Foreign Direct Investment and Free Trade Zone of Developing Nations [J]Economics,2009 (1) : 71-83.

[2] Wang Qin. Regional Economic Integration and Its Effect of ASEAN [J]. Study on Nanyang Problem,2008 (1) : 1-9

[3]Qiu Licheng. Investment Effect Analysis on Regional Economic Integration of EN [J]. Journal of Nankai University,2009 ( 1) :1337-1348.

[4] Wu Qi. Effect Study on Direct Investment of Regional Economic Integration [D]. Thesis of Master's Degree,Zhejiang University,2003。 
[5] Yu Yanrui. FDI Effect Analysis on Free Trade Zone of China-ASEAN[J]. Social Scientist,2007 (11) : 146-147。

[6] Zhu Zhuang. Effect Analysis of Regional Economic Integration on Influence Effect of FDI [D]. Thesis of Master's Degree,Ocean University of China,2009

[7] ] Zhou Yuping, Sang Jieer. Demonstration Study on Effect of China Attracting Foreign Investment on Nations of Southeast Asia Attracting Foreign Investment [J]. Problem of International Trade,2005 (12) : 48-54.

[8] Barry Eichengreen and Hui Tong. Is China's FDI Coming at the Expense of Other Countries NBER Working Paper? 2005(2):36-41

[9] Chen Dening. Economy Coupling Coefficient and Effect Analysis of Hong Kong and Mainland under CEPA [J].Scholar Research, 2014, 1(2): 85-92. 